\title{
WestVirginiaUniversity
}

THE RESEARCH REPOSITORY @ WVU

Graduate Theses, Dissertations, and Problem Reports

2020

\section{Objects of Communication}

\author{
Tyler Stonestreet \\ West Virginia University, Tjs0049@mix.wvu.edu
}

Follow this and additional works at: https://researchrepository.wvu.edu/etd

Part of the Ceramic Arts Commons

\section{Recommended Citation}

Stonestreet, Tyler, "Objects of Communication" (2020). Graduate Theses, Dissertations, and Problem Reports. 7505.

https://researchrepository.wvu.edu/etd/7505

This Thesis is protected by copyright and/or related rights. It has been brought to you by the The Research Repository @WVU with permission from the rights-holder(s). You are free to use this Thesis in any way that is permitted by the copyright and related rights legislation that applies to your use. For other uses you must obtain permission from the rights-holder(s) directly, unless additional rights are indicated by a Creative Commons license in the record and/ or on the work itself. This Thesis has been accepted for inclusion in WVU Graduate Theses, Dissertations, and Problem Reports collection by an authorized administrator of The Research Repository @ WVU. For more information, please contact researchrepository@mail.wvu.edu. 
Objects of Communication

Tyler Stonestreet

Thesis submitted to the College of Creative Arts

At West Virginia University School of Art and Design

in partial fulfillment of the requirements for the degree of

Master of Fine Arts in

Ceramics

\author{
Robert Moore, M.F.A, Chair \\ Shoji Satake, M.F.A \\ Allison Helm, M.F.A \\ Micheal Sherwin, M.F.A
}

School of Art and Design

Morgantown, West Virginia

2020

Keywords: Ceramics, Pottery, Kansas, Garden City, Community, Ritual, Celebration, Handmade, Immigration, Gathering

Copyright 2020 Tyler Stonestreet 


\section{Abstract \\ Objects of Communication \\ Tyler Stonestreet}

This thesis is a description and analysis of the ceramic work of Tyler Stonestreet. This thesis includes images and a description for the thesis exhibition Objects of Communication as well as a discussion regarding the conceptual, technical, and formal content of the work. 


\section{Acknowledgements}

I would like to take this time to thank my graduate committee and the entire faculty of the West Virginia University School of Art and Design for providing me resources and encouragement to explore and develop my voice as a visual artist. I have immense gratitude for my ceramics faculty who constantly challenged me and taught me valuable knowledge. Shoji Satake, Robert "Boomer" Moore, Shalya Marsh, and Jen Allen have genuine care as teachers and their support nurtured my growth as an artist. I would also like to thank Jack Stonestreet, Keianna Thompson,

Joseph Rincones, Charles Chappell, Ike Hill, Antonio Martinez, Scott Steder, Garet Reynek, and Luke Doyle for all you do. 
$\underline{\text { Table of Contents }}$

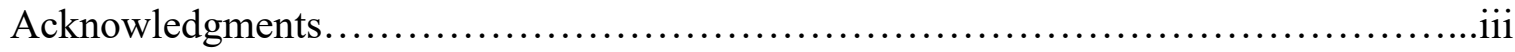

Table of Contents..........................................................

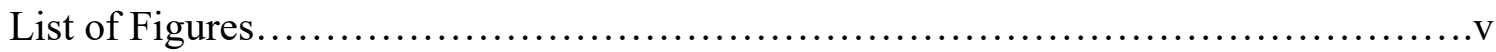

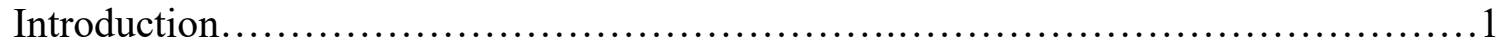

Chapter 1. Culture ..........................................................

Chapter 2. The Work............................................................

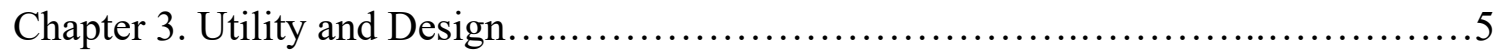

Chapter 4. Process.........................................................

Chapter 5. Influences....................................................... 10

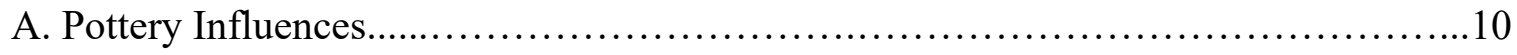

B. Music Influence....................................................... 12

Chapter 6. Objects of Communication........................................ 13

Conclusion.................................................................... 14

Figures................................................................ 16

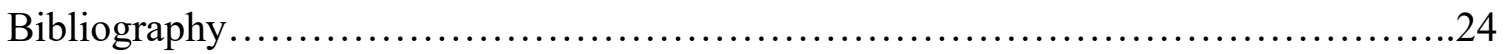

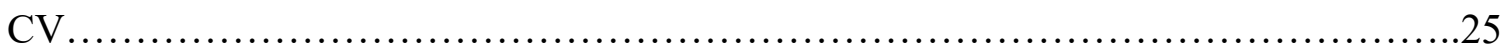


List of Figures

Figure 1. Tyler Stonestreet "Objects of Communication" $2020 \ldots \ldots \ldots \ldots \ldots \ldots \ldots \ldots \ldots \ldots$

Figure 2. Tyler Stonestreet "Grouping of Plates" 2019.............................4

Figure 3. Tyler Stonestreet Sketch book 2020......................................4

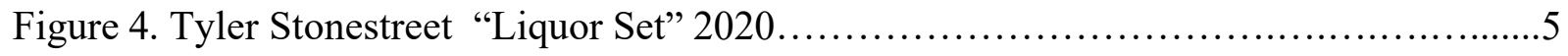

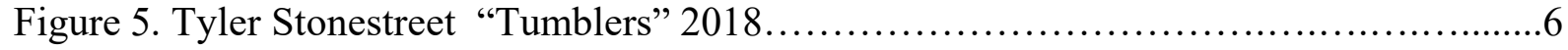

Figure 6. Tyler Stonestreet "Kansas Landscape" 2018................................6

Figure 7. Tyler Stonestreet "Drinking Set" 2018 ...................................

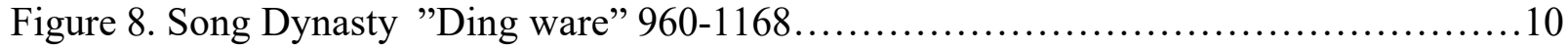

Figure 9. Han Dynasty “Cocoon Vessel” 206 BCE-220 CE 1............................. 10

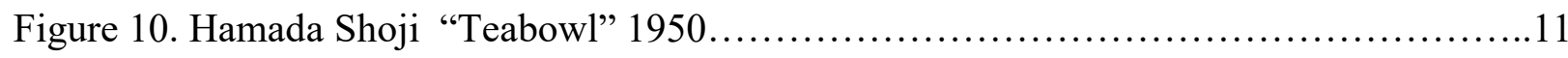

Figure 11. Linda Christianson "Basket" 2019........................................11

Figure 12. Joseon Dynasty "Moon Jar" 1392-1910 ....................................13

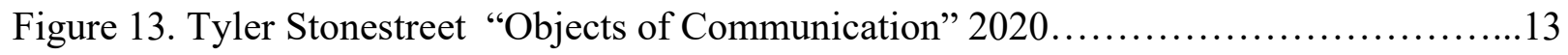

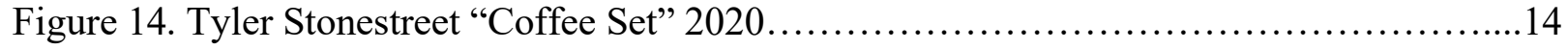

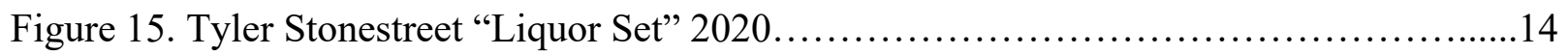

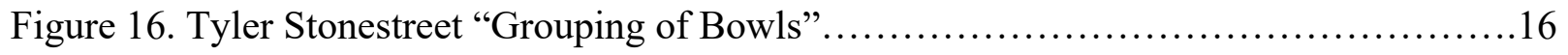




\section{$\underline{\text { Introduction }}$}

My upbringing in an environment that was populated predominantly by minority immigrants had a profound effect on how I view rituals and celebrations. Coming from a white lower-class family, we were a minority in this community. As outsiders, we were welcomed with generous hospitality and acceptance. Our family practices were rooted in western ideals that celebrated the individual instead of the group. Our traditions felt disjointed in their rare occurrences. I found a sense of connection and solace in satellite families. The social constructs amongst immigrant families focuses on collectivism; including strong family ties, expectation for emotional support from one another, loyalty to family, and priority to the family needs over the individual. ${ }^{1}$ These experiences instilled in me, values and customs that celebrate sharing. These values \& customs dictate the way that I live my life and think about making art.

The work that I make encompasses the stories that have shaped me as a person and are a representation of my culture. I consider my culture to be plural as my upbringing was built by diversity. I make pieces that are grouped together to infer they are made for sharing meals. The ritual of celebration was frequent in my upbringing and the regular occurrence nurtured relationships in the community. My work consists of groupings that promote celebration in their use.

In addition to my upbringing, my work pulls inspiration from elements in ceramic history, hip-hop, culture, and nature. My process involves the use of different firing techniques and materials to achieve a desired surface quality. I look to Kansas landscapes as an influence on

1 Vidal de Haymes, Maria, Jessica Martone, Lina Muñoz, and Susan Grossman. 2011. "Family Cohesion and Social Support: Protective Factors for Acculturation Stress Among Low-Acculturated Mexican Migrants." Journal of Poverty 15 (4): 403-26 
these surfaces. Rumination in design aides in the production of thoughtful objects that serve to offer an alternative to monotonous industrial ware and provide contemplation within the user. By working in components, I think of the overall construction of sets and groupings as layers in music that when combined, create a beautiful song. Each component contains consideration of its relationship to one another. This process of building from parts fulfills my curiosity in chance. My pots are made to stand alone as visual objects but when used, have the ability to create meaningful experiences in the user/s life.

\section{Chapter 1: Culture}

I grew up in Garden City, Kansas, which is a small town of roughly 26,000 people. The economy is largely fueled by agriculture and livestock. The town is celebrated for its cultural diversity that functions within close proximity, promoting interaction, and overtime creating an omnipresent sense of pride. $^{2}$ The low-income neighborhoods I grew up in were predominantly populated by families of Southeast Asian and Hispanic descent. The majority of the families worked hard labor jobs at meat-packing plants. The families of my friends and neighbors were so enlivened to share their culture with me that they regularly invited me into their homes. Their hospitality was endless; offering their flavorful cuisine, teaching me their language, and treating me as I was a part of their family. The generous nature of each gesture always made me feel welcome and at home. Even though their wages were low, their lifestyle and mindset felt abundant. I embraced the comfort and ideas of these satellite families who celebrated community, strong family ties, and regular celebration. By embracing what was different, I

2 Broadway, Michael. "Beef Stew: Cattle, Immigrants and Established Residents In a Kansas Beefpacking Town." 
adopted values and traditions from those around me. The pieces that I make are representative of these values in their utility and grouping that promote the sharing of meals.

Celebrations were frequent where I am from and on each occasion; you could expect the repeated question of: "have you eaten?" These gatherings, in each occurrence, were overabundant in food and drink and a welcoming spirit. If it was expected that 50 people were going to attend, there would be enough food to feed 150. Enchiladas, sopa, tamales, and posole were common foods in these celebrations that required long hours of preparation. The hard work and care that went into the preparation of each flavorful dish in accordance with the orchestration of planning was distributed amongst those who took pride in the process yet showed humility by taking no credit when thanked. These selfless actions were common amongst many of my friends' mothers. I want my work to have a similar sense of humility by bringing comfort and beauty into people's daily lives.

\section{Chapter 2: The Work}

In contemporary society, my work is an alternative to the monotony of cold, massproduced, cheap ware. Each piece of my pottery has time and consideration that speak through the tactile and visual qualities. The anonymous quality of industrial ware lacks any connection between the user and maker. ${ }^{3}$ My work is made to invoke contemplation in the user that allows slower moments in their daily life. "To drink from a wax paper cup and a crystal goblet are two different experiences. In the first case, you almost forget that you exist as you drink. In the

3 Boga, Irina. 2016. "Music and Consumerism; the Aesthetics of an Urban Capitalistic Society." 
second, you realize that you have in your hands an instrument that makes you reflect on how you are living in that moment."4

I make familiar utilitarian objects that are associated with daily life and celebration; bowls, plates, teapot sets, liquor sets, coffee service sets, tumblers, and vases (Fig 1). Stands for each set serve to place importance on their grouping and intended shared use. The utility of these objects serves to deliver and contain. ${ }^{5}$ The interaction of sharing food and drink can create or sustain relationships; the pots then serve as vehicles for communication (Fig 2). The use of handmade pottery not only heightens the experience of food and drink but additionally holds the potential to create deeper meaning through use.

The development of form starts in my sketchbook with fast gesture drawings. Drawing quickly produces a line quality that is fluid and confident (Fig 3). I strive to translate that line quality in the final profile of each piece. Constructing these pots in parts enables the opportunity to play, by mixing and matching to find varying solutions of proportion. I find joy in this process as it satisfies my need to problem solve. The symmetry is intentionally offset in the assemblage to encourage a sense of animation. It is important that the forms have a dance when they are constructed on the wheel and I aim to not lose the gesture of dance when immobile. The construction of pots regularly prompts the question: what if? What would happen if the body had more volume? Or how would a taller foot affect this form? The questions that arise feed the aesthetic choices that make up the solution to each piece. I find success in pieces that are closest ${ }^{4}$ Boga, Irina. 2016. "Music and Consumerism; the Aesthetics of an Urban Capitalistic Society." Bulletin of the Transilvania University of Brasov, Series VIII:
Performing Arts 9 (July): 41-48.

${ }^{5}$ Clark, Garth.“Answered Prayers.” Ceramics: Art \& Perception, no.70, Dec.2007, p.102-104. Academic Search Complete. 
in capturing the essence of my drawings. The historical pots that I am inspired by often contain great skill and technique but have "something extra." I find the "something extra" to be within the maker's ability to employ technique but show versatility. This requires immediate decisions that are reactionary and rely on intuition. This ability to embrace what is uncomfortable exerts confidence and fluidity that permit imperfection as intentional and seamless.

\section{Chapter 3: Utility and Design}

Each step in the design; from sketching, to post-fired sandblasting, aides in cultivating a pleasant experience for the user. It is important that each piece feels comfortable to hold and performs its utility with ease. Gestalt principles and the formal elements of design help guide my choices in composition to create beautiful objects. Line, form, tone, texture, and color are amongst these considerations. In addition, compositions are unified in principles of similarity and continuation.

Grouping pots announces the subtle variations of the forms; creating a sense of rhythm and movement through implied lines. (Fig 4) This is created through the off-axis construction method. The geometric stands highlight these qualities by elevating the grouping of pots. It is important that the pots have a sense of softness to have inviting nature. I express this through; spherical volume in form, sandblasted surfaces, fluid line quality in the pots profile, pairing light tones and dark tones, and the combination of contrasting colors. My work also searches for a sense of balance in visual qualities and in the ergonomics. The walls of each piece are made thicker on the wheel to create a sense of durability. It is important that the weight is evenly distributed to provide comfort in use. 
Handles, knobs, and spouts are meticulously modeled to perform their duty with ease and visually accentuate the form. These additive elements either mimic or compliment the existing features of the pot. In my teapots, a knob and handle will mimic the volume of the body to create unity. My work seeks to engage the senses of the user through the addition of important details. I sandblast the exterior and sand the bottoms of each pot to create a tactile quality that is soft and comfortable. The sandblasted surface also reveals a brightened surface quality when it is washed.

A flaring rim is inviting for use and also provides a border to display food. The circumference of each drinking vessel is deliberate in size to enhance the aromas and flavor profiles. Each consideration aides in the user having a memorable experience when using my work.

My choice in color is symbiotic of Kansas landscapes in the spring and fall. Impeding storms often cause an overcast that brightens the contrast between the sky and the ground (Fig 5). The fleeting moments of these landscapes are beautiful and captivating in their temporary nature. I look for a similar composition of color in my work that makes these temporary moments permanent. Warm and cool tones are beautiful when they are paired together. Different clay bodies and firing methods are used to produce these surfaces in my work. The matte, light blue, pots become vibrant and elegant when paired with their stands (Fig 6). The warm tones of the stands are symbolic of the foreground, the cool tones of the pots are symbolic of the sky, and the horizontal line of the stands are symbolic of a horizon line. The surface has a stripped down quality that is quiet and simplistic to promote a sense of wonder and contemplation in the user. 


\section{Chapter 4: Process}

Curiosity is what drives my creative process. I begin with a malleable structure as perimeters and a starting point, trusting that within the process of repetition, honest reflection, and introspection, that the work will evolve. Each iteration is extensive in formalist considerations. By working in a series, imperfections happen naturally exposing variations and nuances that affect future decisions. I find deep satisfaction in each part of the process of making handmade pots.

Experimentation is imperative to my process in cultivating growth and evolution. My time as a graduate student gave me the opportunity to try new processes in making. These include; slip-casting, mold-making, hand-building, 3-D printing, and slab construction (Fig 7). The trial and error of configuring new processes gave me a deeper understanding of the material and its limitations.

I use the potter's wheel to quickly make parts that are combined to compose each pot. The actions of making each part are recorded in the clay and show my hand through the imperfections. By working modular, I think of the overall construction of sets and groupings as layers in music that when combined, can create a beautiful song. Each component pays careful consideration of its relationship to one another. The construction of my pots is rigorous in iteration to find a solution of line that feels confident and skillfully drawn like those expressed in my initial sketches.

I make pots from porcelain clay and the stands out of red clay with an application of local slip. I am fascinated by different clays and their inherent qualities. The fine particles of porcelain require more sensibility and closer attention to each step in making. Porcelain provides a white surface that brightens glaze and when struck creates a beautiful, bell-like ring-tone. Its ability to stretch provides more fluidity in my work; from its creation on the wheel to the formal 
qualities in the finish piece. Historically, porcelain was reserved to emperors and imperial families, and its introduction to the west through the silk road created high demand globally. Its reverence as a material holds a history that is rich in wonder.

Equally, I find as much meaning in the use of red clay as I do with porcelain. The historical importance of its second-class status and unpretentiousness nature has resonance to my upbringing. In addition to the historical attributes, it has a forgiving nature that is less susceptible to warping and cracks when fired. It is more commonly associated with utilitarian lower-class wares. Historically, red clays were easily found and highly used in populations containing the same imagery and ideals of the ruling class. Red clay holds an unpretentious nature that is inviting for use and embodies a "creative spirit." ${ }^{\text {I }}$ am fascinated by the historical relationship to class in the use of different clays. I use stoneware and porcelain to refer to my upbringing in a lower-class community. Even though we were limited in our resources, we still accessed and wanted objects of value. Our limited access created reverence to the objects that we had. The collective mindset within my community also encouraged the sharing of these objects.

I fire the stands for drinking sets in a natural gas soda kiln in a reduction atmosphere. I introduce sodium carbonate into the kiln at cone $9\left(2336^{\circ} \mathrm{F}\right)$. Sodium carbonate is sprayed into the kiln in a liquid form through a commercial sprayer that I have modified to withstand high heat. Once introduced to the kiln, the sodium carbonate vaporizes and follows the path of the flame through the kiln reacting with the alumina, silica, and iron content of the clay. Sodium carbonate forms as a glaze on the stands showing a visual record of the flame path in the kiln.

6 McKeough, Tim. "Why Handmade Ceramics Are White Hot." The New York Times. December 16, 2015. https://www.nytimes.com/2015/12/17/fashion/why-handmade-ceramics-are-white-hot.html. 
Although this process has predictable outcomes, I enjoy the element of surprise that the soda kiln offers. The element of chance is a refreshing part of the process.

I fire the kiln in a reduction atmosphere and control this process through the damper system and natural gas burners. This achieves a burner atmosphere that has more fuel than it does oxygen. I maintain this atmosphere until a maturing temperature of cone $9\left(2336^{\circ} \mathrm{F}\right)$. Once reaching my maturing temperature in the kiln, I seal up any openings with newspaper and clay slip, turn off a burner, shut the damper system, and reduce to the lowest setting on the remaining burner. This achieves keeping the kiln in a reduction atmosphere while cooling. I continue the process of cooling the kiln until the kiln reaches $1700^{\circ} \mathrm{F}$ by going down in temperature $100^{\circ} \mathrm{F}$ per hour. Keeping the kiln in an oxygen-starved atmosphere on the cooling process doesn't allow the pieces to re-oxidized fully. This firing process in conjunction with my use of indigenous clay that contains high levels of iron oxide, allows me to achieve various colors and surface qualities. The porcelain pieces are fired in a natural gas kiln. The atmosphere of the kiln is reduced. I fire the kiln to the maturing temperature of cone $11\left(2381^{\circ} \mathrm{F}\right)$ to receive a dense body. I have modified a glaze to contain a low amount of red iron oxide and using this firing procedure and clay body produces a soft blue.

Whether it involves experimenting with a new clay, trying a new construction method, or deconstructing a glaze formula. The result of experimentations sometimes offer answers but mostly pose questions. The questions that arise feed my curiosity as a maker. I find comfort in exploring what is unfamiliar as the results support the burgeoning of new possibilities. 


\section{Chapter 5: Influences}

Being open to experiences has allowed me a chance to see the world from different perspectives. My work draws inspiration from artwork that has had a lasting impact on me. Connections are made to the past and present that are combined with my personal experience to create objects that are representative of me. My influences serve as the starting point in creating my work. I draw inspiration from the beauty in the world.

\section{A. Pottery Influence}

Ding ware was produced in China from the Tang Dynasty (618-907) until the Jin Dynasty (1115-1234) and was among the top 5 porcelains produced during the Song Dynasty (960-1127). ${ }^{7}$ It is known for its whiteness, thin walls, strength, and chime-like sound when tapped with your finger. The pots were decorated with stamping methods in addition to highly skilled carvings of religious motifs (Fig 8). Ding ware was highly sought after in its time and reserved for the imperial court. Its pure white quality and intricate decoration on robust forms exalted a softness and elegance in its essence. I was moved the first time seeing this ware in china by its simplicity in color, elegance in form/decoration and its celebration of material.

The cocoon vase from the Han Dynasty (206BC-220AD) are lively in their combined use of bright lead glazes, organic decoration, and swelling volume. These forms are playful, yet elegant (Fig 9). In Figure 9, the size of the foot in relation to the body gives elevation to the form highlighting the volume of the mid-section. The swelling volume in this ovoid vase adorned with swirling motifs appears to combine wheel turned components with hand-built. Confidence in line is shown in the execution of form and skillful brushstrokes. I am fascinated by early works like these that show innovation and creativity.

7 Song Xiaoyan. 2018. "Ding Ware, as White as Snow and as Lustrious as Jade.” China Today 67: 74-75 
In addition to ancient pottery and its influence on my work, I have been directly influenced by the philosophy of Japanese ceramics and the "Mingei" movement. This movement was celebratory of folk art; finding beauty in the everyday, utilitarian objects that were made by the common people. ${ }^{8}$ Yanagi Soetsu, Hamada Shoji, and Kawai Kanjiro were the founders of this movement and their friendship with British potter Bernard Leach brought these ideas to the West.

Hamada Shoji, one of the founders of the mingei movement, preached ideas and ethics of a "good pot" and what it consisted of. He emphasizes the significance of simplicity and function and the importance of being open and responsive at that moment when making. ${ }^{9}$ The importance of being open and responsive dictates the visual confidence in the finished piece (Fig 10). Regular practice in my studio has increased my understanding and carrying out of this concept. As my technical skills increase so does my ability to react to the material. Making parts on the wheel incorporates this process by working quickly and allowing shapes to be in the ballpark. The process of letting go permits variety in groupings through the subtle nuances of each piece.

An american potter that I have had the pleasure of meeting is Linda Christianson. She is a potter from Minnesota that creates simplistic, straight forward pottery (Fig 11). She strives to make pots that perform their utility well and "stand on their own as a visual object." ${ }^{10}$ As the relationship between the maker and user is important to me, I admire the work not only for its

\footnotetext{
${ }^{8}$ Leach, Bernard. The potters challenge. New York: Dutton, 1975
}

${ }^{10}$ Silberman, Robert 2013. "Linda Christianson.” Ceramics: Art \& Perception, no. 92 (June): 12-13. 
honesty and simplicity but based on her personality and kindness she has shown me each time we have crossed paths. The humbleness of her character is admirable as well as the unpretentiousness nature of her pots.

\section{B. Music Influence}

Hip-hop is a part of my daily life and is influential in the way I think of making pottery. Songs often contain a certain feeling that the composer is trying to invoke. Dr. Dre is a key artist that I look to for inspiration in my work. His music is not overloaded in complexity but each decision seems very intentional. He pulls from different factions of society and history to create something expressing their aesthetic. Sampling is a part of each of their processes that combine consumption and production. ${ }^{11}$

In the beginning of hip-hop, deejays would repeat parts of the song that were favored by the crowd. As hip-hop evolved, the samples used to create songs became more descriptive of the producer's style. By scanning rhythms, sounds, symbols, phrases, and melodies that are linked to culture; they transform them into something new. The complex grouping of sounds when put together creates new meaning. This process is part of active listening and part production. Instead of bending notes like in jazz, hip hop artists and composers rearrange existing elements to create the composition.

Dr. Dre was revolutionary in his ability to create a sound of the west coast. Coining “gfunk" as the genre he produced, his meticulous beats were relaxed and fluid. Instead of using samples directly, he would look to samples for inspiration and have musicians to live play them

\footnotetext{
${ }^{11}$ Rice, Jeff. "The 1963 Hip-Hop Machine: Hip-Hop Pedagogy as Composition." College Composition and Communication 54, no. 3 (2003): 453-71.
} 
for him to record. ${ }^{12}$ This allowed him the freedom to alter and edit aspects that directly sampling did not permit. In nothing but a $\mathrm{G}$ thang, he borrowed elements from Leon Haywoods, 'I wanna do something freaky to you" and added a basic Bassa Nova percussion and a whining anthem sine synthesizer substituting the melody, becoming that main sound of g-funk. His inclusion of the Minimoog synthesizer took recognizable sounds from disco that when paired with his bass lines, and percussion became a staple of west coast hip-hop.

The way that Dr. Dre pulled and borrowed elements of existing material to create his own sound is closely related to my process of making pottery. I often borrow elements from historical ceramics that strike me. The process of working in sections began with my fascination with moon jars that were made in Korea during the Joseon Dynasty (1392-1910). They combined two wheel-thrown bowls to create spherical jars. These jars are celebrated for their asymmetry and the visible seam that connects the two halves (Fig 12). They are a rejection of artificial ideals and a celebration of natural beauty. My work is inspired by the unpretentious nature of these jars and the creative spirit.

\section{$\underline{\text { Objects of Communication }}$}

The exhibition Objects of Communication is a graduate thesis show that celebrates a blending of historical and contemporary influences into the importance of using handmade pottery. The pieces in the show included teapot set, cocktail set, tumbler set, ewer set, liquor bottle set, a serving bowl, a grouping of bowls, a grouping of plates, and vases. The title of the show refers to the utility of the pots in their grouping that promote shared celebration (Fig 13).

12 Kajikawa, Loren. "“Let Me Ride”: Gangsta Rap’s Drive into the Popular Mainstream." In Sounding Race in Rap Songs, 85-117. Oakland, California: University of California Press, 2015. 
This body of work consists of utilitarian pottery that are associated with daily life and celebration. They are organized groupings that have specific utilities tied to ritual. Each grouping and set is considered as a visual composition abiding by formal elements and gestalt principles. It is important that the pottery performs their utility but also functions as beautiful objects. Stands serve to visually heighten the importance of each set to indicate their utility as ritualistic. Most of the sets in the exhibition have a utility that is specific to sharing beverages whether it is a coffee set for two (Fig 14), or a tumbler set for four (Fig 15). The groupings of pots that don't have stands are bowls and plates that are stacked in multiples (Fig 16).

My upbringing in a multicultural environment instilled in me values that nourished a collective ideology that promotes frequent social gatherings. Within the gallery, the sets and groupings along with their familiar utility are meant to send visual cues to the viewer that spark their imagination of how they would use each set and who they would share that experience with. My works strive to invoke a sense of contemplation. The implementation of ritual is produced through any consideration of an action performed. By using pottery that I make, these moments become an enriching part of daily life and celebrations.

\section{Conclusion}

The use of different firing techniques, materials, and construction methods granted space and freedom in making this body of work. My mother always said, "if you are comfortable, you are not growing." My upbringing taught me at a young age that much can be gained by embracing what is uncomfortable. These ideas were an elemental force to making this body of work. Embracing different processes and materials produced a sense of excitement in every step 
of the process. This feeling of excitement was produced through fear, failure, and chance. Working this way helps me feel in the moment when making and continuously presents an opportunity to learn. My pottery celebrates sharing in the utility and groupings that they are organized in. Growing up in a multicultural environment introduced me to ideas that were different from those of my own family and helped shape my values. I feel that my experience on this earth has been unique and my goal as an artist is to look inward to express the essence of what is authentic to me. Ceramics has offered me a platform and opportunity to share my experience

\section{$\underline{\text { Figures }}$}

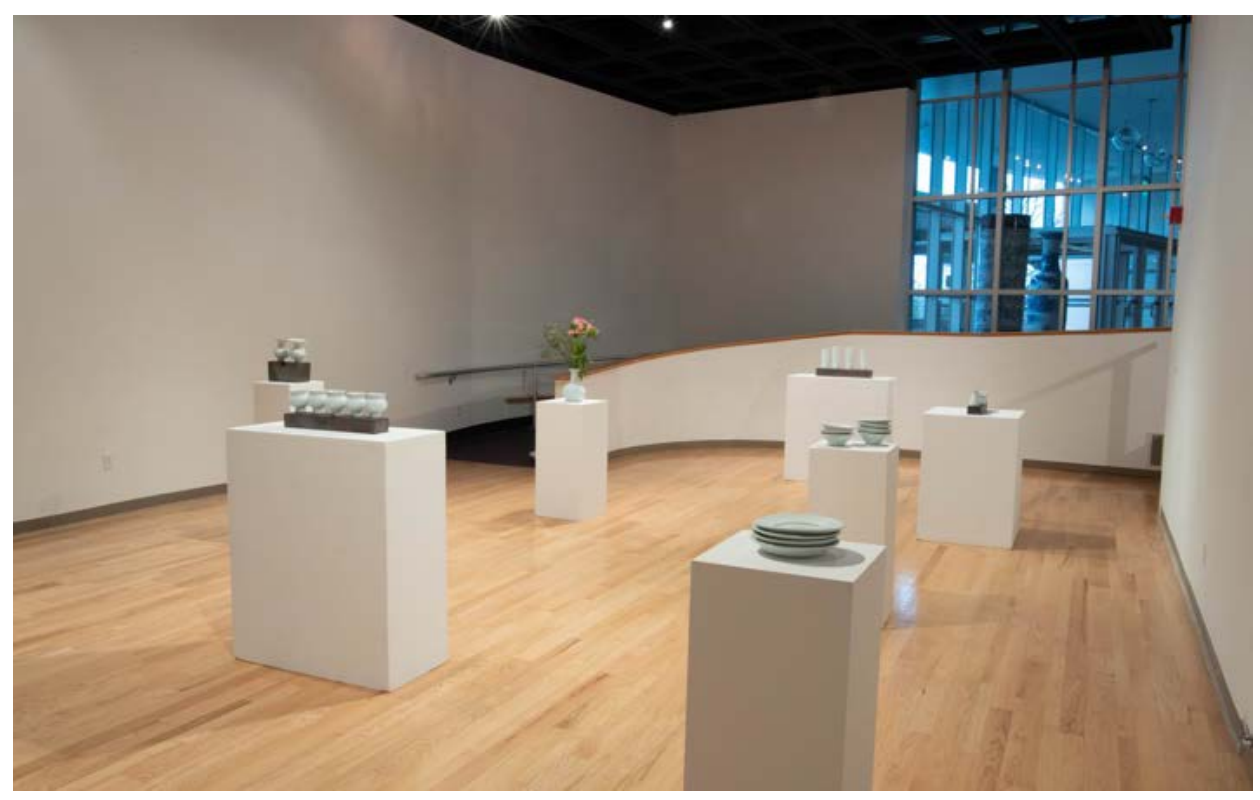

Fig. 1. "Objects of Communication" 7 x 20 x 4. Porcelain, Stoneware, Local slip. Cone 11 Reduction, Cone 9 Reduction cooled. Sandblasted. 


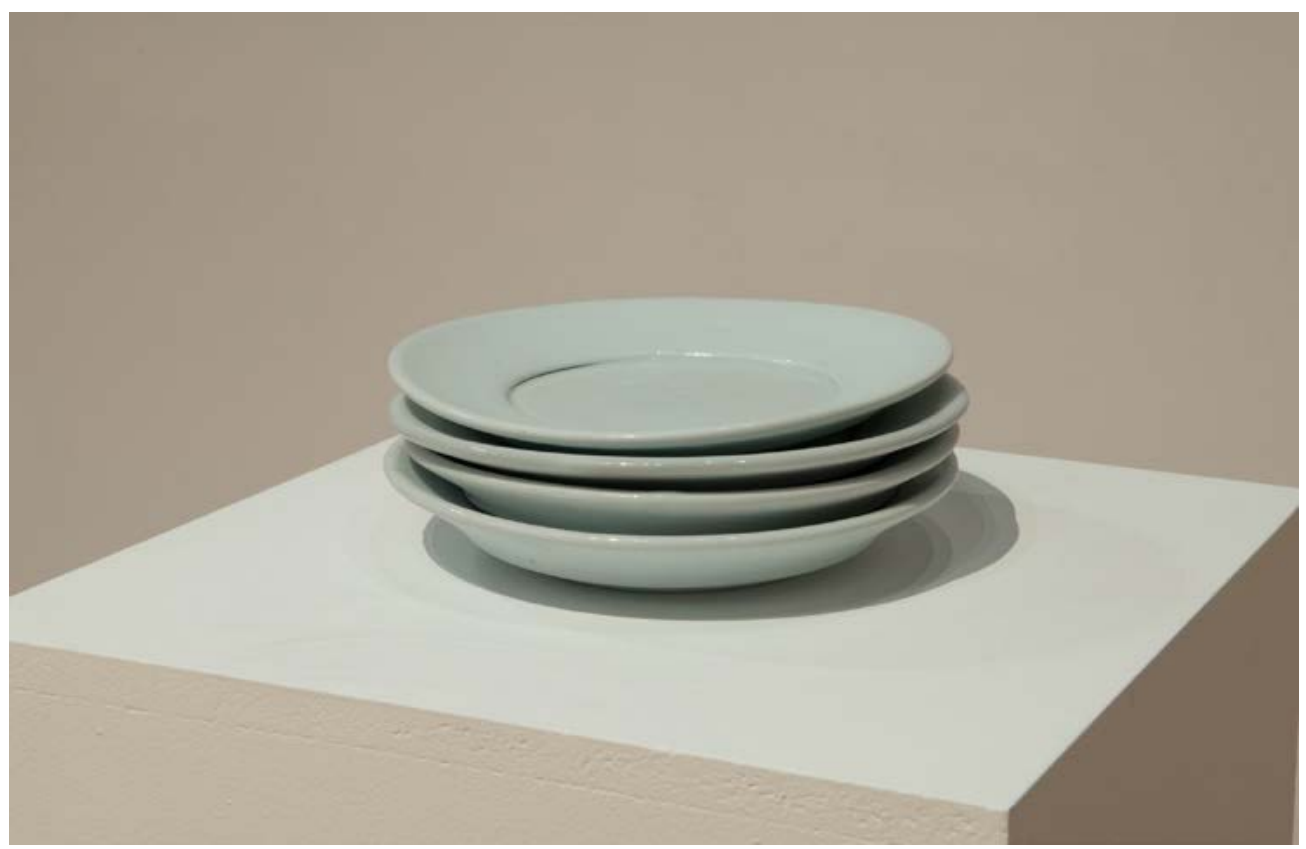

Fig. 2. "Grouping of Plates" 7 x 20 x 4. Porcelain, Stoneware, Local slip. Cone 11 Reduction, Cone 9 Reduction cooled. Sandblasted.

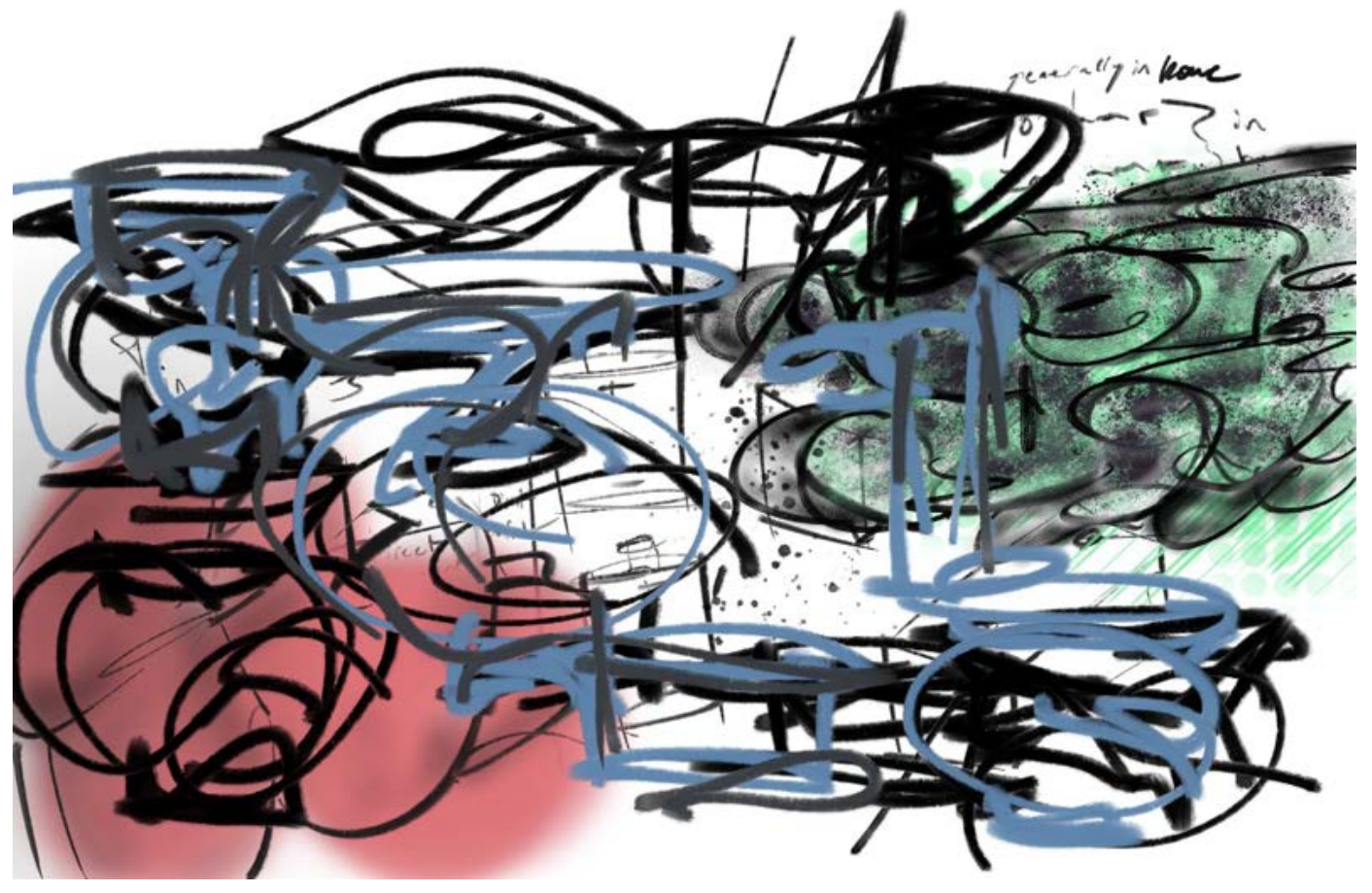

Fig. 3. Sketchbook. Drawing by Tyler Stonestreet 


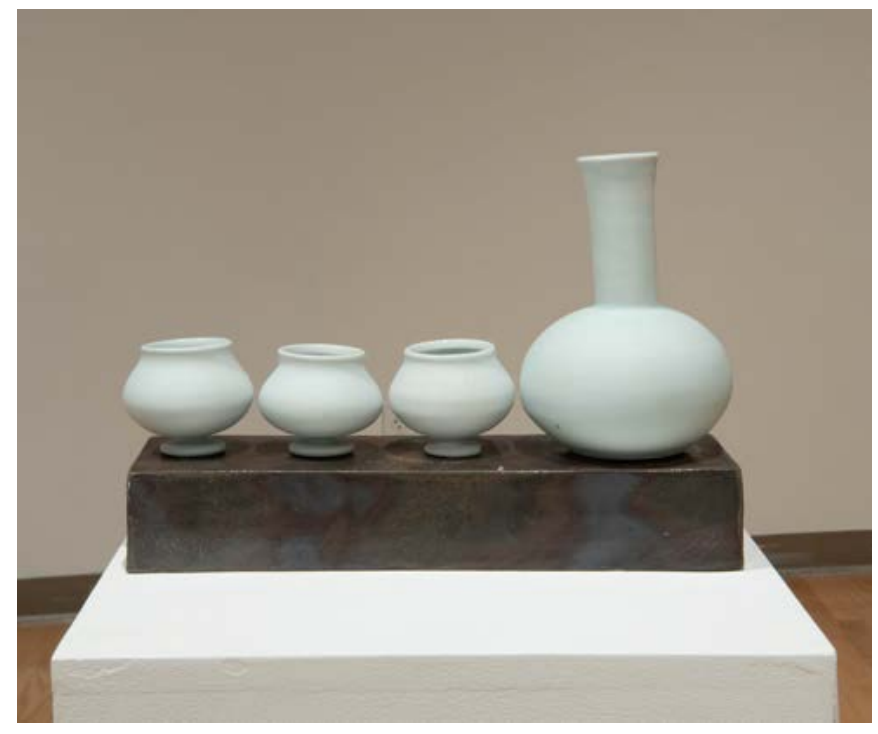

Fig. 4. "Liquor Set" 7 x 16.5 x 5.5. Porcelain, Stoneware, Local slip. Cone 11 Reduction, Cone 9 Reduction cooled. Sandblasted.

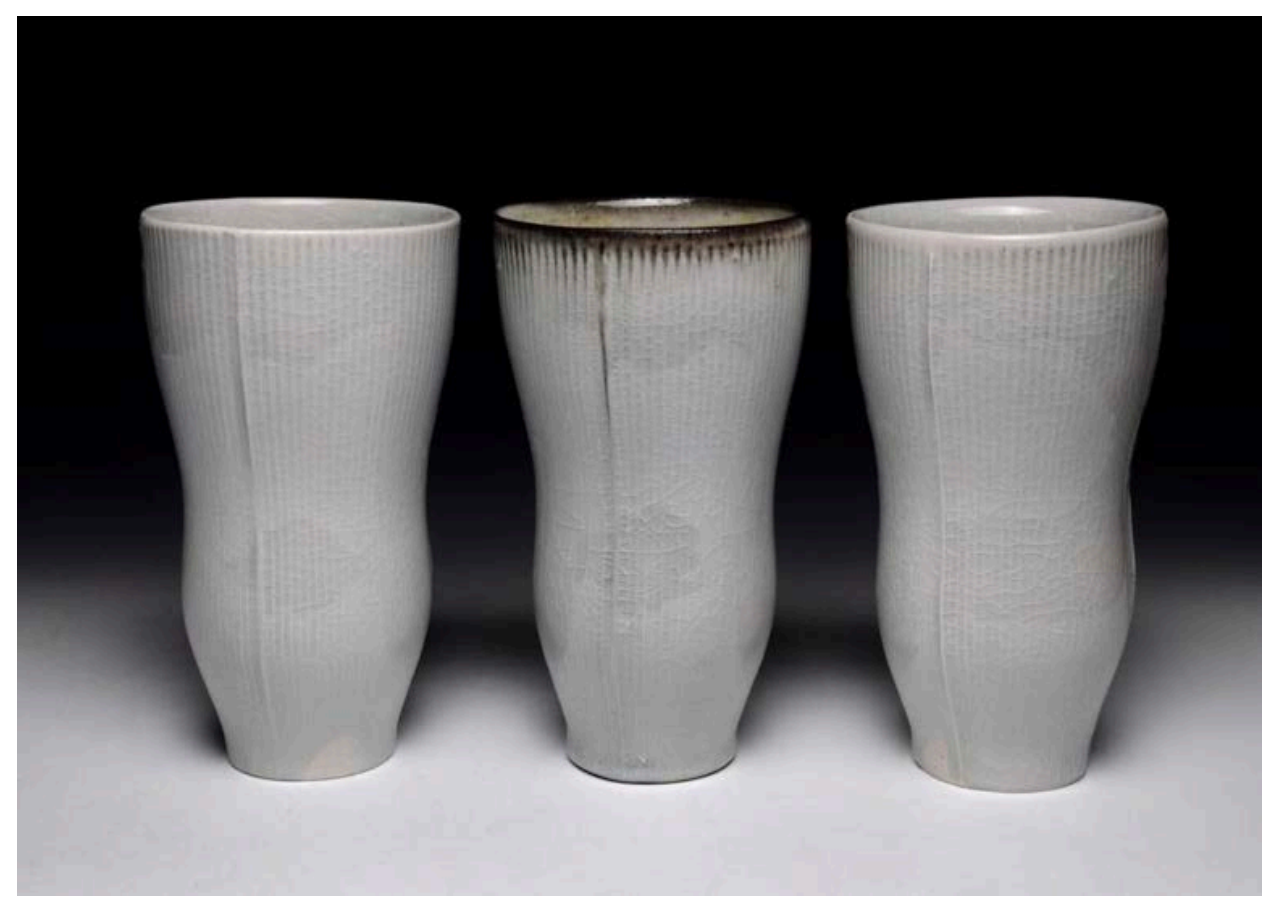


Fig. 5. "Tumblers" 8 x 3 x 3 Porcelain, Slip-Casted, 3-D Printed Mold. Cone 10 Reduction.

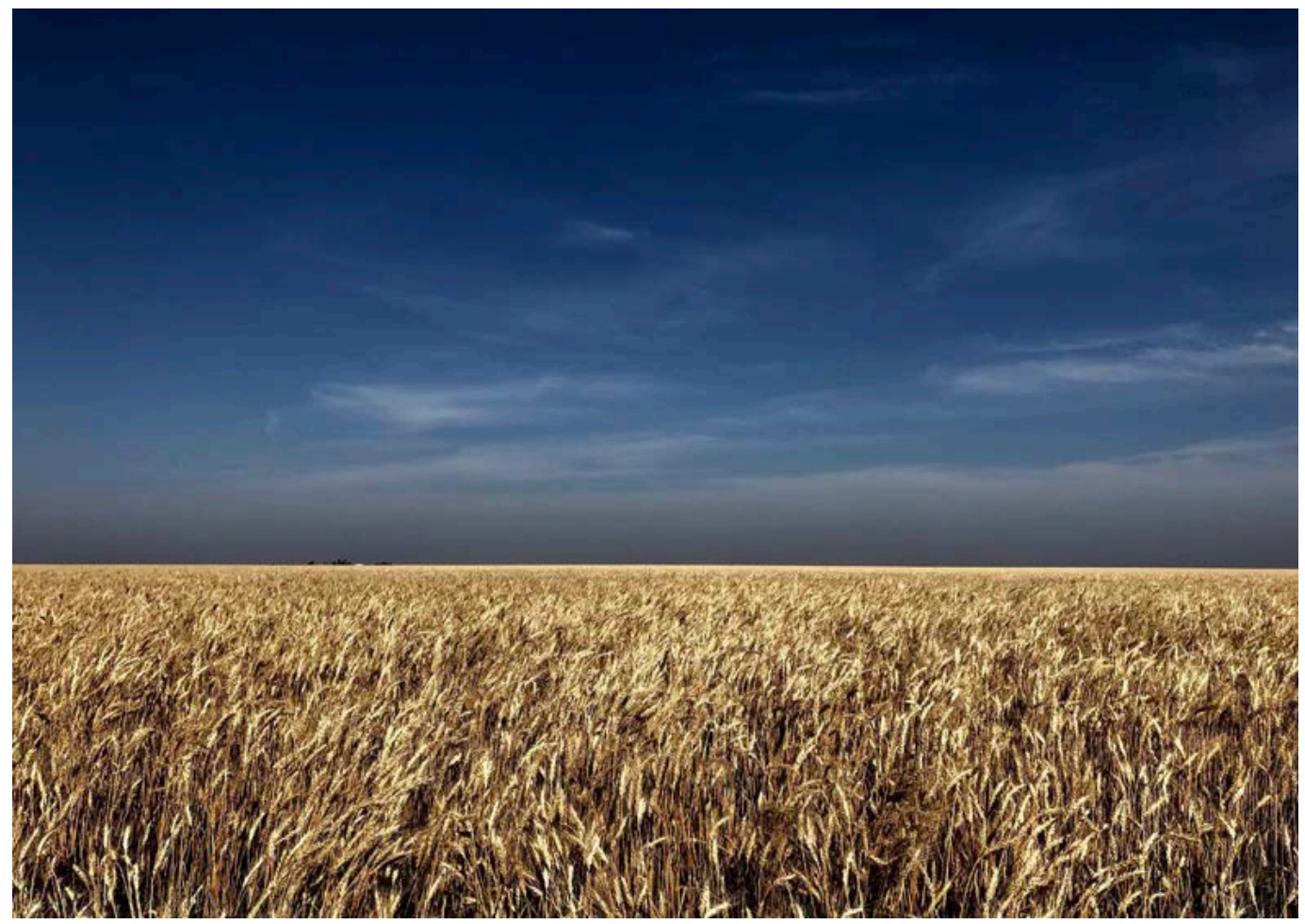

Fig. 6. Kansas Landscape. Photo Taken by Tyler Stonestreet

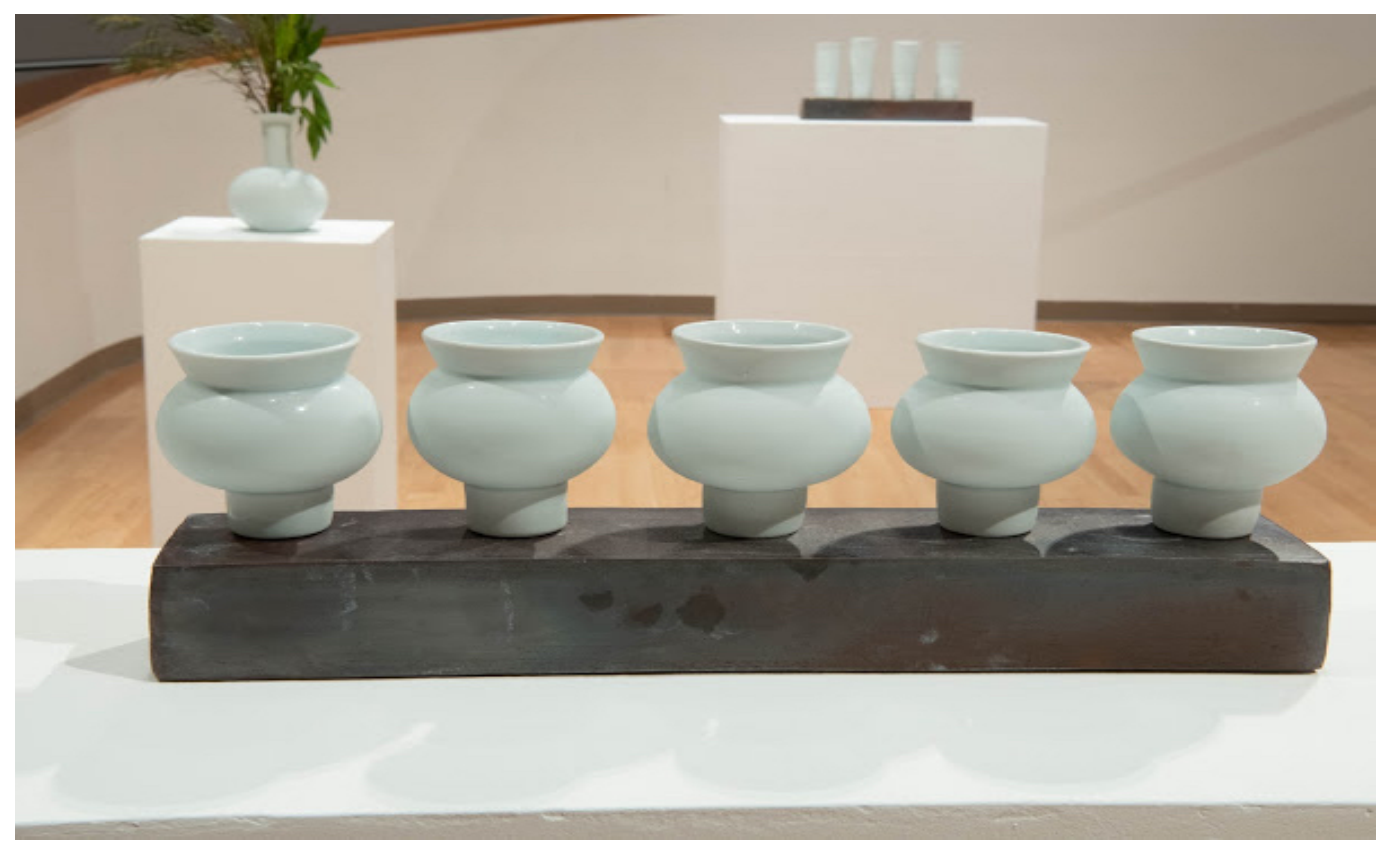

Fig. 7. "Drinking Set" 7 x 20 x 4. Porcelain, Stoneware, Local slip. Cone 11 Reduction, 
Cone 9 Reduction cooled. Sandblasted

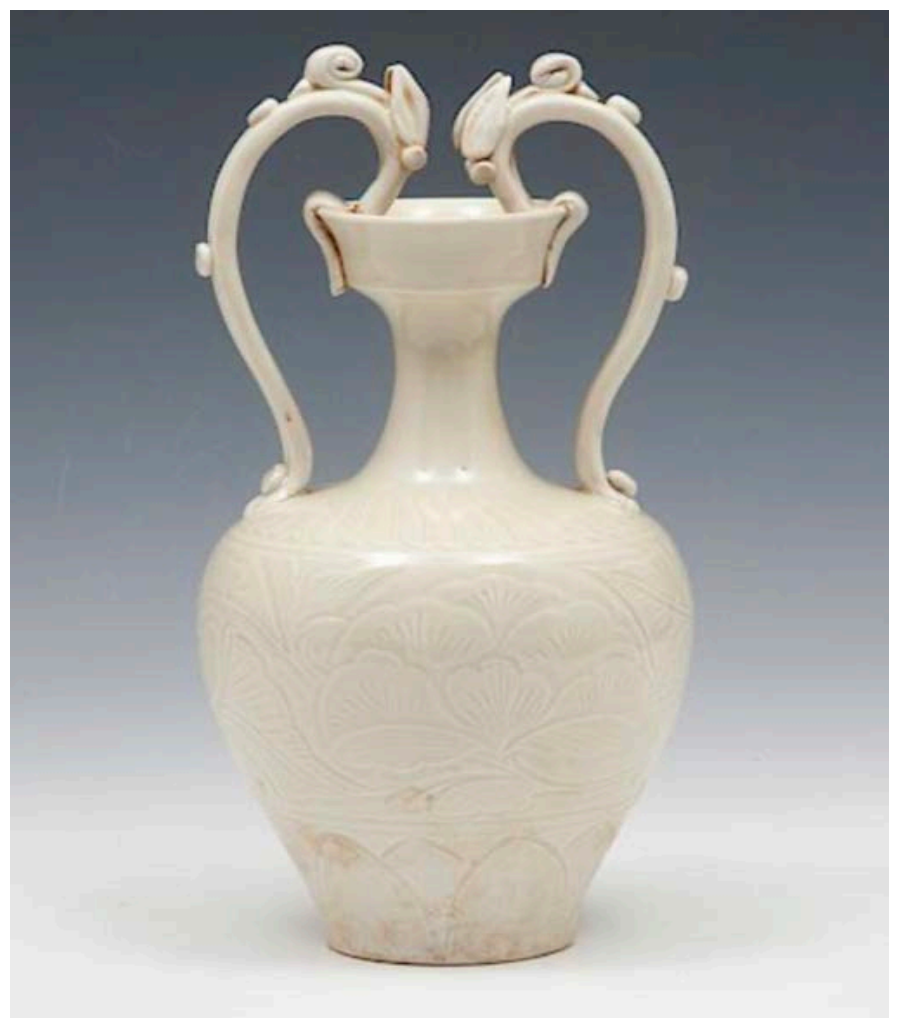

Fig. 8. "Jar" Ding ware, Song Dynasty, China. 960-1279.

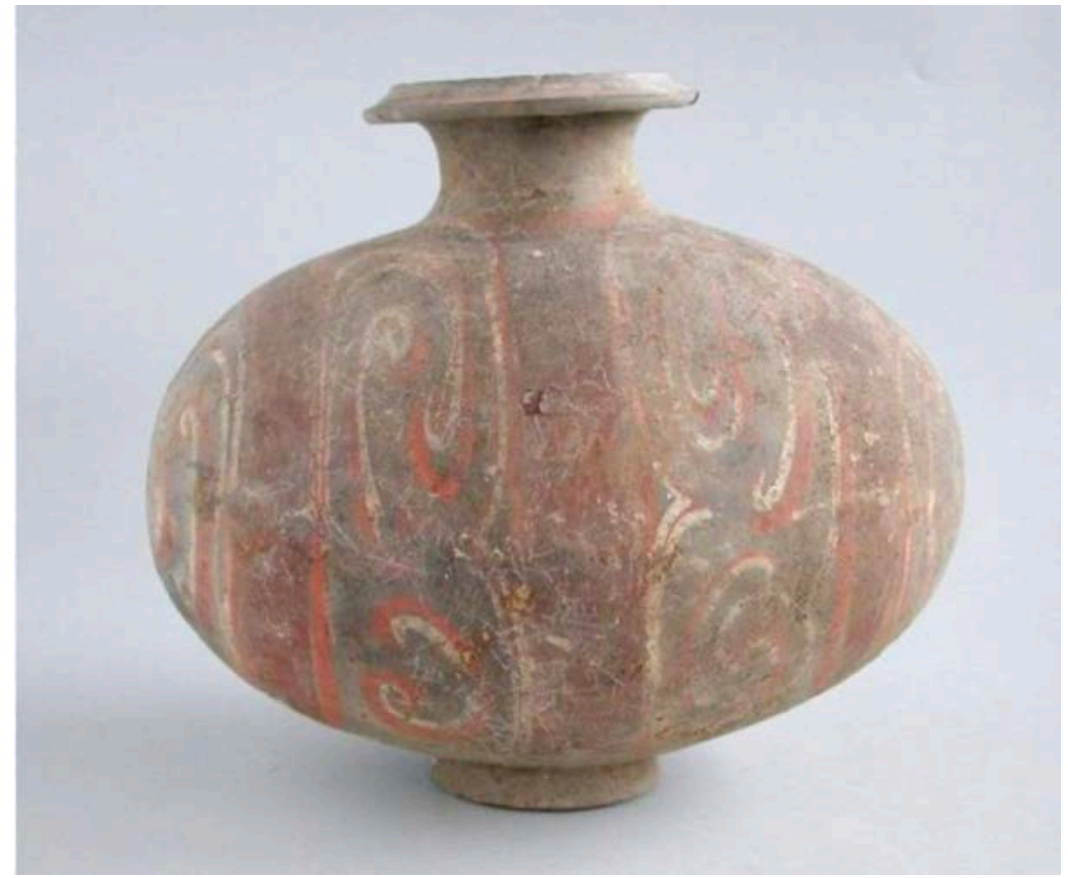


Fig. 9. "Jar" Han Dynasty, China. 206 BCE-220 CE.

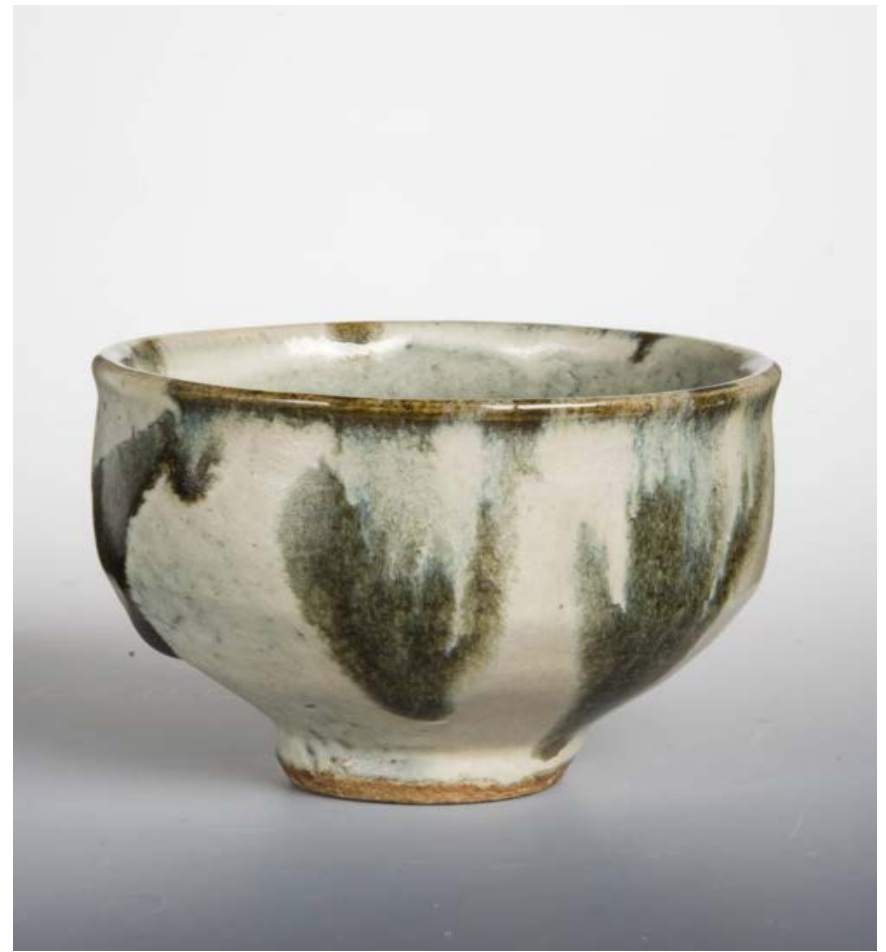

Fig. 10. "Teabowl” Hamada Shoji. Japan. 1950.

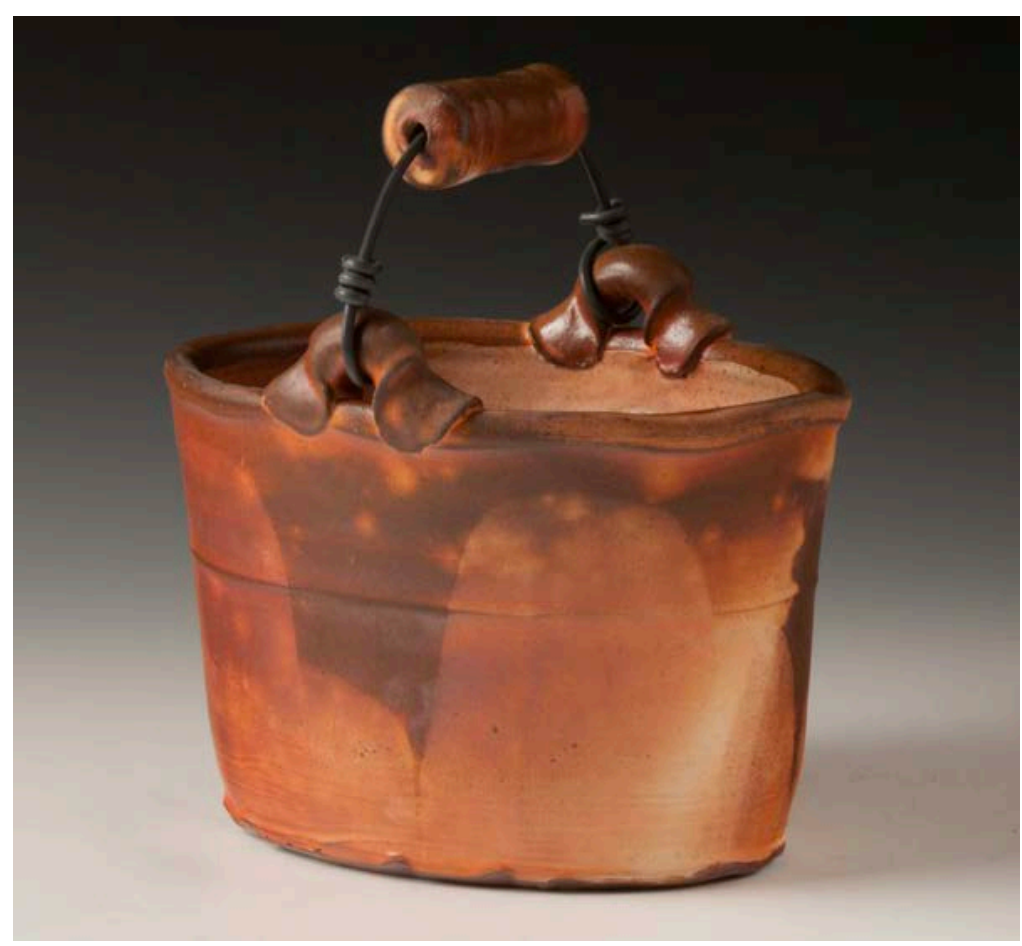


Fig. 11. "Basket” Linda Christianson. USA. 2019.

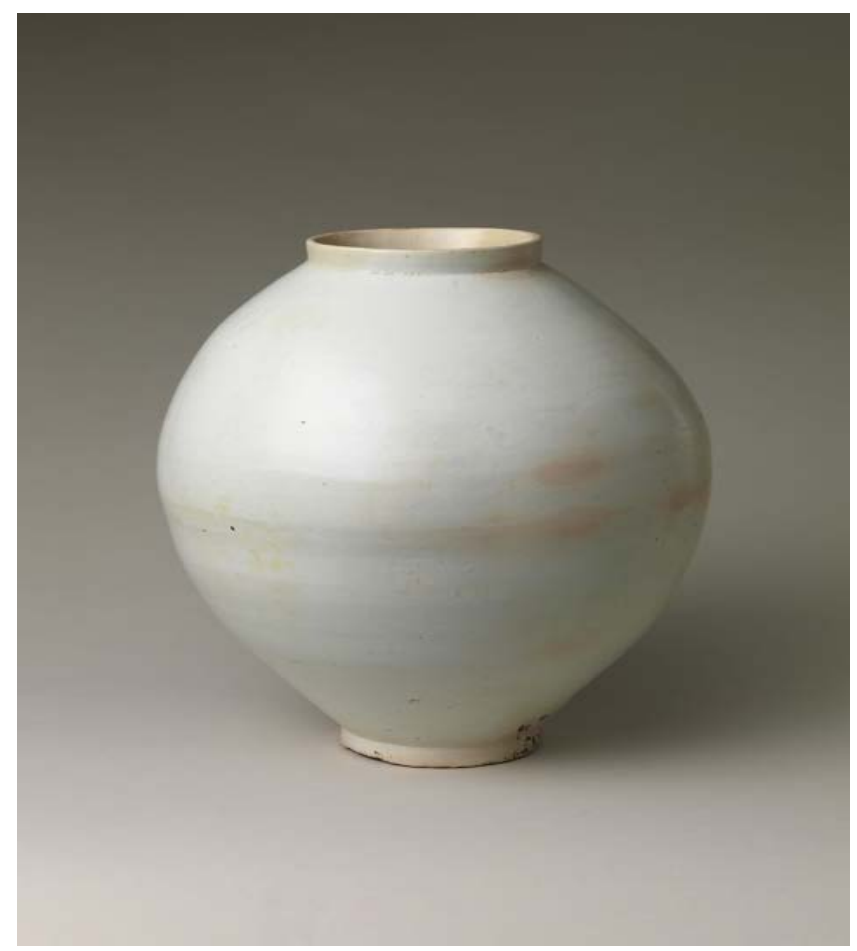

Fig. 12. "Moon Jar" Joseon Dynasty, Korea. 1392-1910.

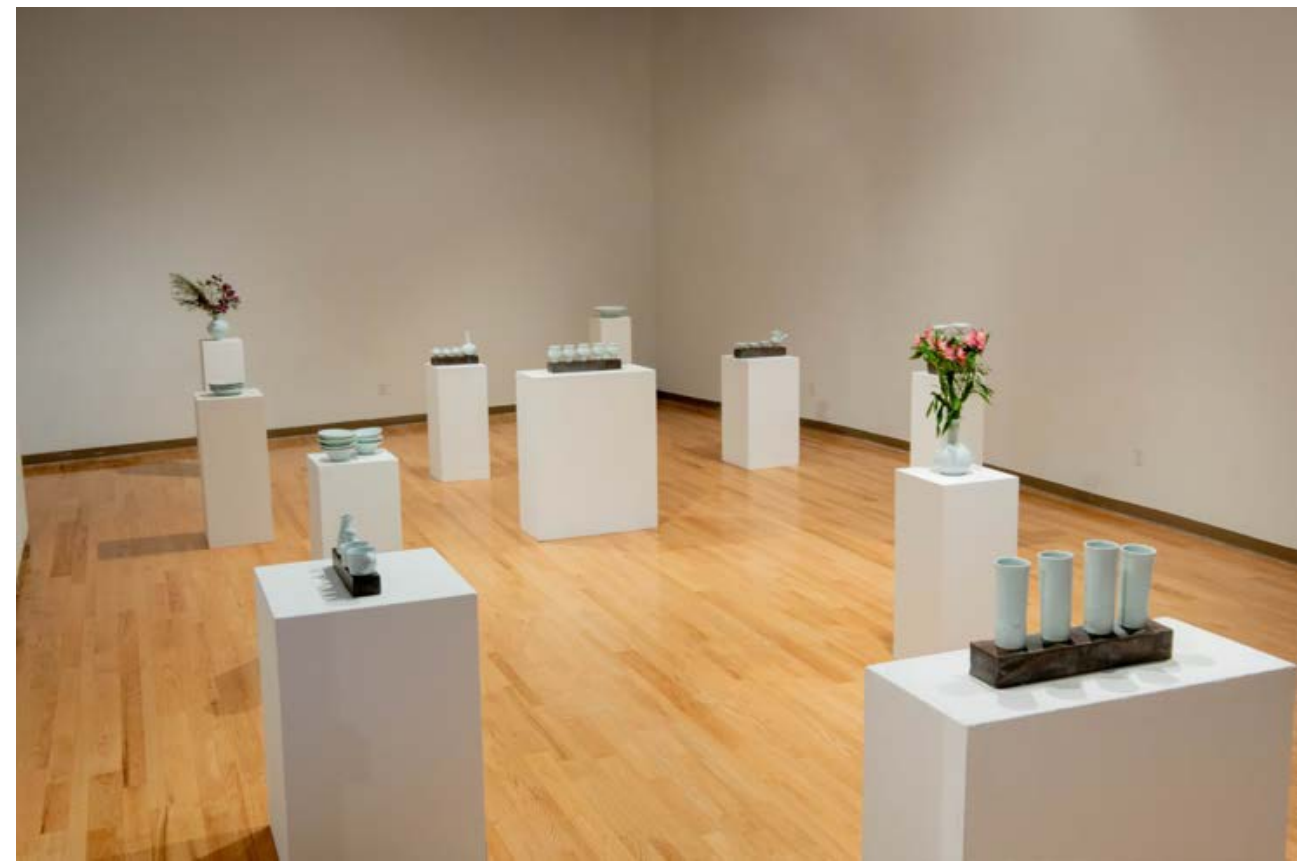


Fig. 13. "Objects of Communication" 2020.

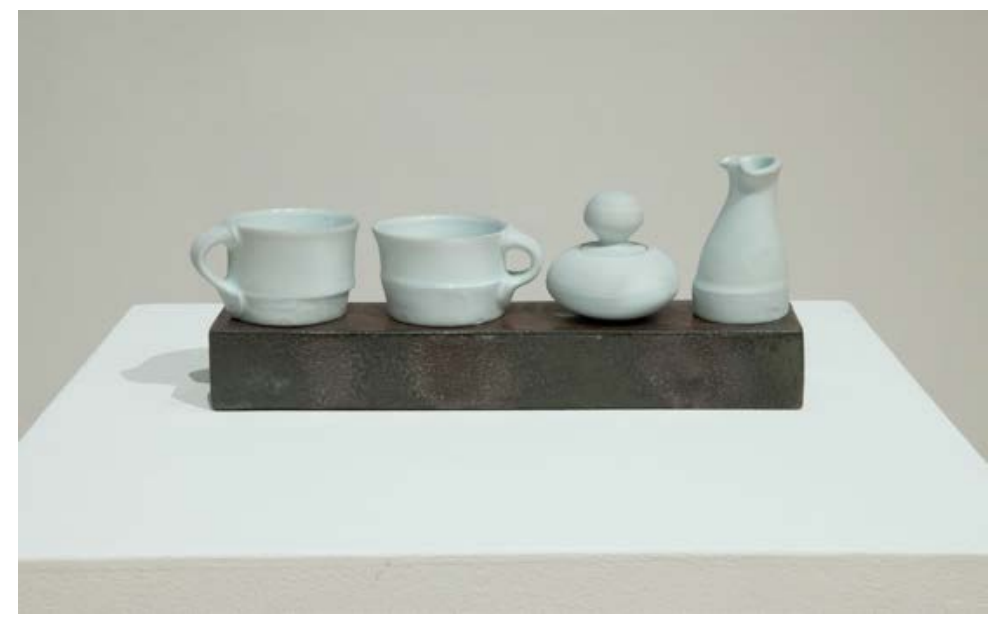

Fig. 14. "Coffee Set" 7 x 17 x 4. Porcelain, Stoneware, Local slip. Cone 11 Reduction,

Cone 9 Reduction cooled. Sandblasted.

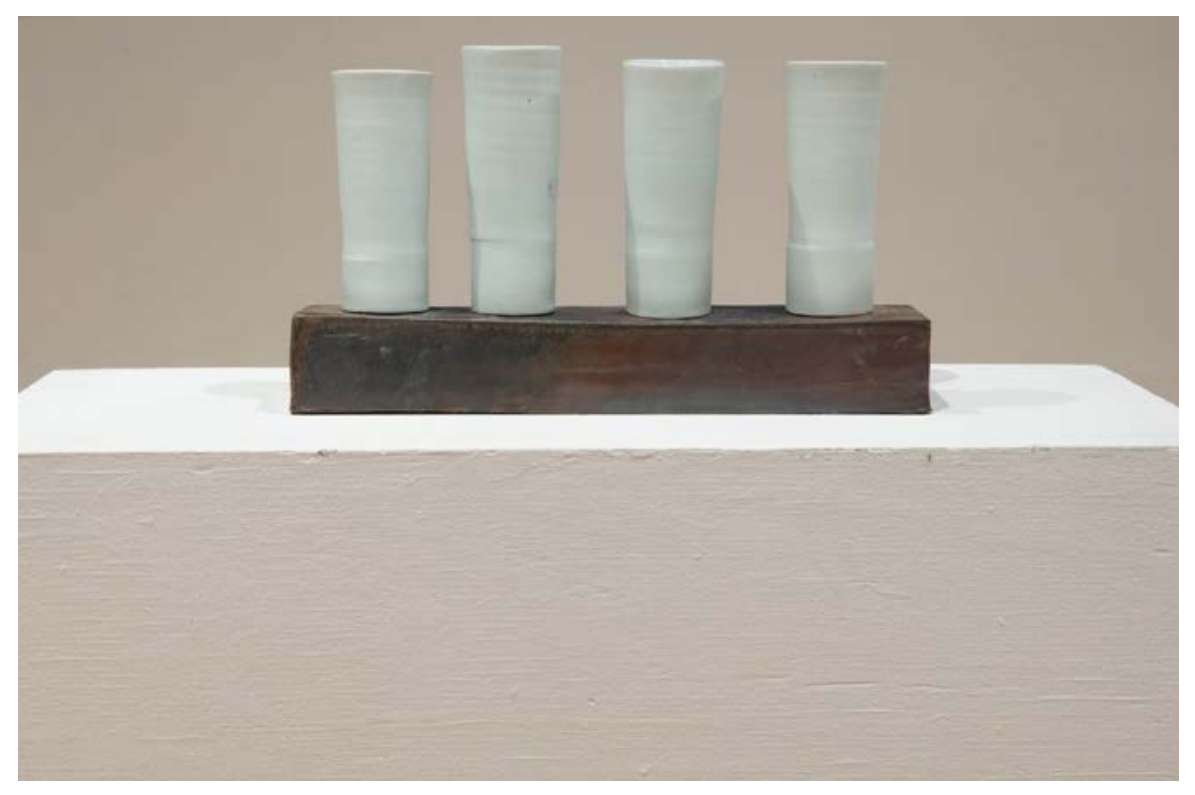

Fig. 15. "Liquor Set" 7 x 16.5 x 5.5. Porcelain, Stoneware, Local slip. Cone 11 Reduction,

Cone 9 Reduction cooled. Sandblasted. 


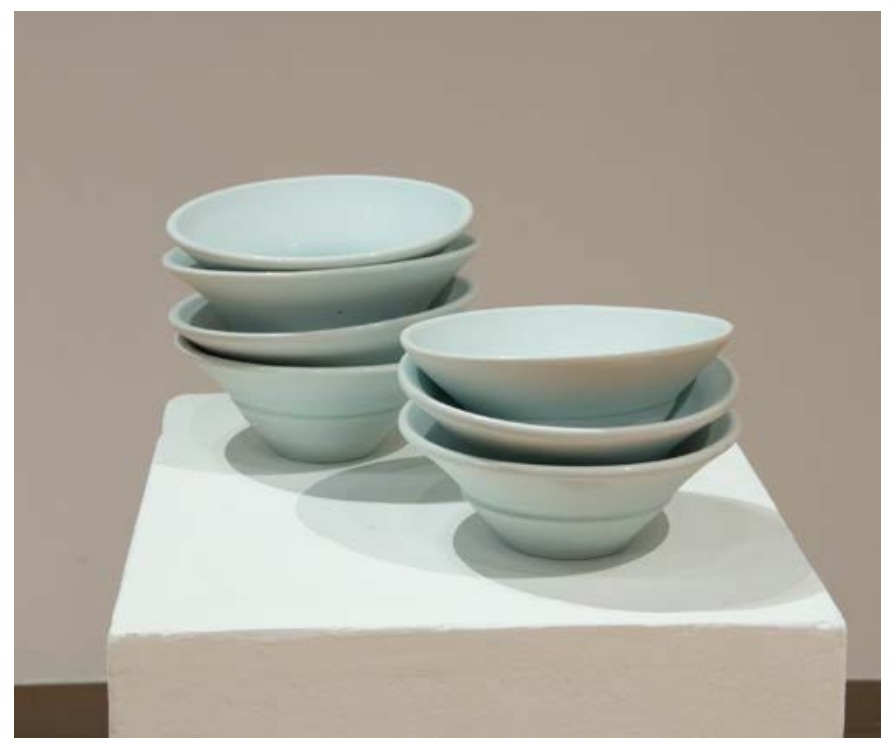

Fig. 16. "Grouping of Bowls" 12 x 18 x 18. Porcelain, Stoneware, Local slip. Cone 11

Reduction, Cone 9 Reduction cooled. Sandblasted.

\section{Bibliography}

Boga, Irina. 2016. "Music and Consumerism; the Aesthetics of an Urban Capitalistic Society." Bulletin of the Transilvania University of Brasov, Series VIII: Performing Arts 9 (July): 41-48.

Broadway, Michael. "Beef Stew: Cattle, Immigrants and Established Residents In a Kansas Beefpacking Town." In Newcomers In Workplace: Immigrants and the Restructing of the U.S. Economy, edited by Lamphere Louise, Stepick Alex, and Grenier Guillermo, 25-43. Temple University Press, 1994.

Clark, Garth.“Answered Prayers.” Ceramics: Art \& Perception, no.70, Dec.2007, p.102-104. Academic Search Complete.

Kajikawa, Loren. "“Let Me Ride": Gangsta Rap's Drive into the Popular Mainstream." In Sounding Race in Rap Songs, 85-117. Oakland, California: University of California Press, 2015. McKeough, Tim. "Why Handmade Ceramics Are White Hot." The New York Times. December $16,2015$.

Leach, Bernard. The potters challenge. New York: Dutton, 1975 
Rice, Jeff. "The 1963 Hip-Hop Machine: Hip-Hop Pedagogy as Composition." College Composition and Communication 54, no. 3 (2003): 453-71.

Silberman, Robert. 2013. "Linda Christianson.” Ceramics: Art \& Perception, no. 92 (June): 12 13.

Thompson, Candice. 2019. “Stretch Yourself.” Dance Magazine 93 (1): 130-32

Song Xiaoyan. 2018. "Ding Ware, as White as Snow and as Lustrious as Jade." China Today 67: $74-75$

Vidal de Haymes, Maria, Jessica Martone, Lina Muñoz, and Susan Grossman. 2011. "Family Cohesion and Social Support: Protective Factors for Acculturation Stress Among LowAcculturated Mexican Migrants." Journal of Poverty 15 (4): 403-26

Yanagi, Sōetsu, and Bernard Leach. The unknown craftsman: a Japanese insight into beauty. New York: Kodansha USA, 2013.

\section{Tyler Stonestreet} 3408 N. Fairview Wichita KS, 67204 (681) 209-1995

Tylerstonestreetceramics@gmail.com

\section{$\underline{\text { Education }}$}

2017-Present

MFA Ceramics Emphasis, West Virginia University, (2020).

2013-2016

BA Ceramics Emphasis, Wichita State University.

\section{$\underline{\text { Exhibitions }}$}

2020

"Objects of Communication." Laura Mesaros Gallery.

Morgantown, West Virginia.

2019

“Breath from Afar.” Taoxichuan Ceramic Art Avenue.

Jingdezhen,

China. 
“Taoxichuan International Exibition.” Taoxichuan Ceramic Art Avenue. Jingdezhen, China.

“Affair.” Fiber Studio. Wichita, Kansas

2017

“Found in Translation.” Mufei Gallery. Jingdezhen, China.

“Flow(er).” WSU Shiftspace Gallery. Wichita, Kansas.

2016

“Chapter 1.” Wichita City Arts. Wichita, Kansas.

“Advanced Project Student Network Exibition.” Red Lodge Clay Center. Red Lodge, Montana.

“Akar Yunomi Invitational.” Akar Architecture and Design. Iowa City, Iowa.

2015

Finding My Voice. Cadman Gallery. Rhatigan Student Center. Wichita, KS

\section{$\underline{\text { Artist Residencies }}$}

2019

2018

2017

2016
American Museum of Ceramic Art (AMOCA) 1-month residency

American Museum of Ceramic Art (AMOCA) 1-month residency.

Pottery Workshop Jingdezhen. 3-month residency.

Advanced Student Project Network (ASPN.) 3-week residency.

Red Lodge, MT.

American Museum of Ceramic Art (AMOCA) 1-month residency. 
